\title{
IMAGENS (DES)ENQUADRADAS NA FORMAÇÃO DE PROFESSORES: O QUE PODE O COLETIVO ESCOLAR EM TEMPOS DE PANDEMIA?
}

\author{
(DES) FRAMES IN TEACHER EDUCATION: WHAT CAN THE SCHOOL COLLECTIVE \\ IN PANDEMIC TIMES?
}

\author{
Hociene Nobre Pereira Werneck ${ }^{1}$ \\ Lívia Camporez Giuberti ${ }^{2}$
}

\begin{abstract}
Resumo: Este artigo problematiza como professoras ${ }^{3}$ têm (re)existido como corpo coletivo no cotidiano escolar em tempos de pandemia. Utiliza-se da cartografia e de seus fluxos imprevisíveis para movimentar o pensamento e, por meio de rede de conversações, capturar a força de ação coletiva em formações de professoras ocorridas em meio ao distanciamento social. Entendendo a força de ação coletiva como processo de resistência, mergulha nas imagens geradas durante os encontros online cartografando afetos alegres e tristes. Argumenta que as docentes experimentam, criam, resistem e (re)existem diante das trocas e aprendizagens. Nesse sentido, discute o tempo da escola como tempo que rompe com experiências cronológicas e provoca fugas às imposições e às limitações do ensino remoto, promovendo interações e (des)enquadrando imagens estáticas que potencializam outros modos de viver os cotidianos escolares.
\end{abstract}

Palavras-chave: Formação de professores; cotidiano escolar; Força de Ação Coletiva.

\begin{abstract}
This article discusses how teachers have (re) existed as collective body in the school's routine in the pandemic period. Cartography and its unpredictable flows are used to move thought and, through a network of conversations, to capture the force of collective action in teacher training that took place in the middle of the social distance. Understanding the force of collective action as a process of resistance, deep dive in the images generated during the online meetings mapping happy and sad affections. He argues that teachers experience, create, resist and (re) exist in the face of exchanges and learning. In this sense, discuss school time as a time that breaks with chronological experiences and causes escapes from the impositions and limitations of remote education, promoting interactions and (un) framing static images that enhance other ways of living school daily life.
\end{abstract}

Keywords: Teacher education; school life; Collective Action Force.

\section{Criar é resistir: cartografia de movimentos de resistências e invenções curriculares na formação de professores em tempos de pandemia}

Pera aí, caiu! Não ouvi nada. Liga o seu áudio, tá desligado! Que buzinação é essa aí fora? Que lindo, dá para ouvir os sons dos pássaros, você tá no meio da floresta? Não tenho tempo para nada. Vamos ter que fazer uma rotina para orientação, quem é voluntário para ir semana que vem? (Redes de conversações com professoras - Diário de Campo - 2020).

Os fragmentos remetem à captura de enunciações de professoras que ecoam por esta cartografia e que, por vezes, silenciam-se diante dos contextos singulares dos encontrosformação pelas telas dos computadores. Pelas redes de conversações (CARVALHO, 2009),

\footnotetext{
${ }^{1}$ Universidade Federal do Espírito Santo-UFES, ES, Brasil.

${ }^{2}$ Universidade Federal do Espírito Santo-UFES, ES, Brasil.

${ }^{3}$ Utilizamos o termo professoras no feminino, destacando a presença de mulheres como participantes e integrantes do corpo docente da escola pesquisada.
} 
movimentamos o pensamento com professoras de um Centro Municipal de Educação Infantil no município de Serra/ES e levantamos a seguinte inquietação: Como professoras têm (re)existido como corpo coletivo no cotidiano escolar em tempos de pandemia?

Apostando na potência dos encontros e no fluxo de experiências com o cotidiano escolar, atravessamos um contexto de distanciamento social e de ensino remoto que, em meio à pandemia do coronavírus (Covid-19), tem transformado as relações e os modos de viver os processos educativos com a escola. Nesse sentido, o texto aposta na captura de afetos, afecções e processos de resistências que atravessam as telas e conectam professores nos encontrosformação, abordando a força de ação coletiva em meio aos novos espaços de formação de professores. Que tensões o distanciamento tem provocado nas formações de professores?

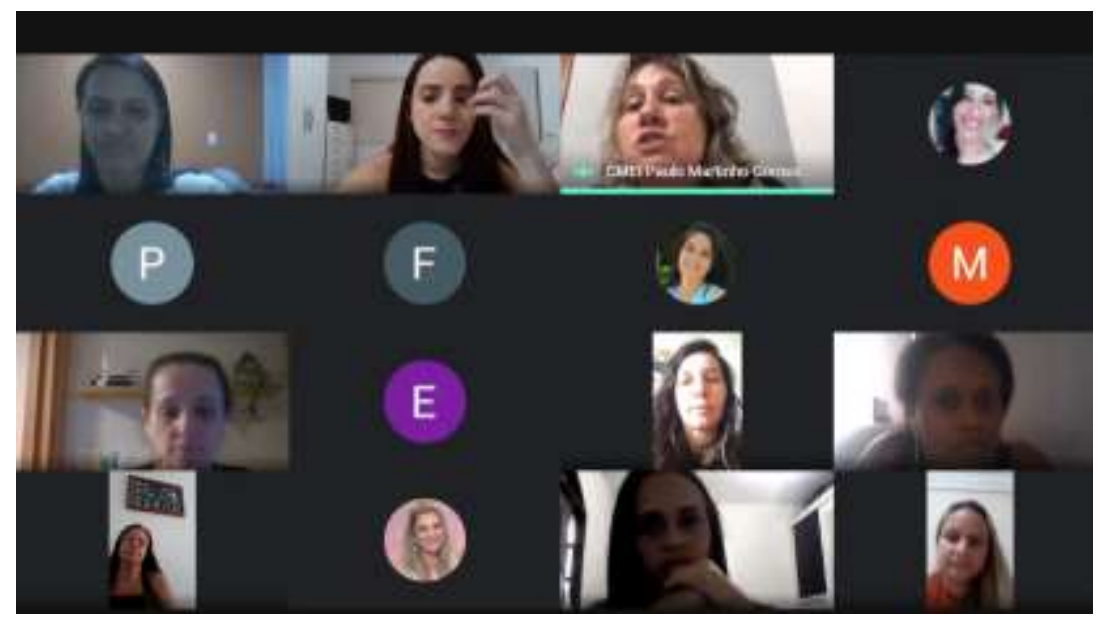

Figura 1 - Formação de professores via aplicativo Google Meet - Fonte: arquivo próprio (2020).

Carvalho, Silva e Delboni (2018, p. 808) indicam que "[...] os corpos coletivos, em meio às redes de conversações, potencializam a vida em composição com forças heterogêneas no plano de imanência, em um processo de invenção, que provoca deslocamentos nos movimentos curriculares". Por esse motivo, fizemos a escolha de iniciar a escrita do presente texto com enunciados de professoras que nos sinalizam a existência de outros modos de se fazer currículo e de estar coletivo no cotidiano escolar em pleno período de pandemia. As telas que enquadram também promovem imagens outras de (des)enquadramento dos corpos. Os processos formativos deste tempo em que vivemos invadem diversos espaços, em que professoras utilizam as telas de dispositivos eletrônicos, como a de computadores, tablets, telefones celulares, para se conectarem com outros docentes, movimentando o pensamento em meio ao distanciamento social.

Acreditamos que, embora o distanciamento social e o contexto pandêmico insistissem na tentativa de capturar a vida ante os afetos tristes (SPINOZA, 2009) produzidos por imposições, regramentos, vazios, ausências, reclusão, dentre outros, a força de ação coletiva (CARVALHO, 2009) persiste produzindo resistências, fissurando os engessamentos curriculares impostos pelos documentos e orientações de órgãos oficiais, culminando na invenção de outras possibilidades de vida no cotidiano escolar e nos espaços de formação de professores.

As "resistências" a que nos referimos não se relacionam à oposição, “[...] mas, sobretudo, desconstrução, transgressão, burla e táticas produzidas nas redes cotidianas, em relação ao que está posto como norma, como determinação, como modelo" (CARVALHO, 2009, p. 4). Assim, ao resistirem aos modelos impostos, professoras criam novas possibilidades de aprendizagem e de existência, como processos de (re)existência, conforme enunciam em suas redes de conversações: 
- Semana passada fizemos um vídeo de acolhida e agora estamos preparando as atividades. Aprendi a fazer até um avatá. (Risos) Ficou muito legal. Temos uma colega que domina melhor a informática e que nos ajuda bastante. Juntas somos mais fortes!

- Lembra que comentei com você sobre o papel do professor pesquisador? Isso ficou bem forte pra mim. Nunca pesquisei tanto para produzir essas atividades on-line.

- A vantagem, nesse período de pandemia, é o fato de agora termos formações, porque antes não podíamos deixar a sala de aula. Agora a gente tem lives de todos os lados. (Redes de conversações com professoras - Diário de Campo - 2020).

O encontro com o inusitado da pandemia não foi capaz de paralisar o movimento de criação, pois coletivamente as professoras compartilharam ideias, conhecimentos, sugeriram novas maneiras de se encontrarem para planejamentos, para momentos formativos, etc. As redes de solidariedade e cooperação foram alternativas para as dificuldades com o uso das tecnologias, já que o sistema de ensino adotou o modelo de teletrabalho para o exercício das suas funções.

Entretanto, dentre as capturas que fizemos ao longo deste tempo sensível, muitos malabarismos não adentram às telas delimitadas dos computadores. Como experimentar aprendizagens remotas? A precariedade do trabalho docente que atravessa o período da pandemia aparece na narrativa de professoras que confirmam utilizar seus aparelhos particulares para produzir movimentos curriculares remotamente (computador, celular). Os encontros e conexões realizadas custam a internet e a energia elétrica pagas, custa o tempo não quantificável de horas extras e preparações complexas em meio às novas tecnologias, custa o tempo com a família e com afazeres domésticos que não existiam em meio às atividades laborais.

O medo do novo, da incerteza, da insegurança, da doença, das imposições encontra os corpos como um afeto triste que, diante da real possibilidade de contágio pelo novo coronavírus (Covid-19), afeta na medida em que diminui a potência de agir de muitas professoras.

Contudo, sem negar a existência desses afetos tristes, estamos em busca de investigar a força de ação coletiva na/da escola produtora de resistências que impulsionam a constituição de um comum plural (CARVALHO, 2009), potencializador dos movimentos inventivos curriculares em tempos de pandemia. Entendemos que o comum nada tem a ver com consenso ou com homogeneização, mas como "proliferação de atividades criativas, relações ou formas associativas diferentes" (CARVALHO, 2009, p. 162), que é construído na relação com o outro, na articulação de conversações e ações, em meio a convergências e divergências de ideias.

E foram muitas atividades criativas que proliferaram através dos múltiplos modos de se relacionarem. Ideias que se transversalizaram, povoando os espaços de formação. Nessa perspectiva, a criação desses novos modos de interação via meio remoto (WhatsApp, Google Meet, vídeos...) também se configura em uma forma de resistência à imobilização do movimento nos/dos cotidianos escolares. A proliferação de conversas, reuniões, encontros remotos é tentativa de manter viva a força coletiva de professoras? De criar possíveis para a escola? Uma professora questiona durante um encontro on-line:

- Por que nunca pensamos isso antes? Por que não promovíamos mais espaços para encontros com professores em horários acessíveis, sem ser tão corrido como aqueles que ocorriam no final do dia na escola? (Redes de conversações com professoras - Diário de Campo - 2020). 
Segundo Deleuze e Guattari (2010, p. 142), o ato de criação se constitui como força intensiva, energia das resistências, pois "[...] criar é resistir". Assim, podemos afirmar que há diversas possibilidades de resistências. Possibilidades que potencializam a produção de outros sentidos para o currículo, mesmo em contexto de pandemia, como demonstrado nas redes de conversações com professoras durante o processo formativo:

- Vi seu status. Que pessoa chique, gente! (Pesquisadora)

- É para o nosso vídeo. Estou ansiosa para ver o produto final. (Professora)

- Qual vídeo? Tão chique assim? (Pesquisadora)

- O vespertino irá fazer um vídeo para a semana das crianças. Vamos fazer brincadeiras via Meet. Vamos fazer por grupos. Fiz até maquiagem. (Professora) (Redes de conversações com professoras - Diário de Campo - 2020).

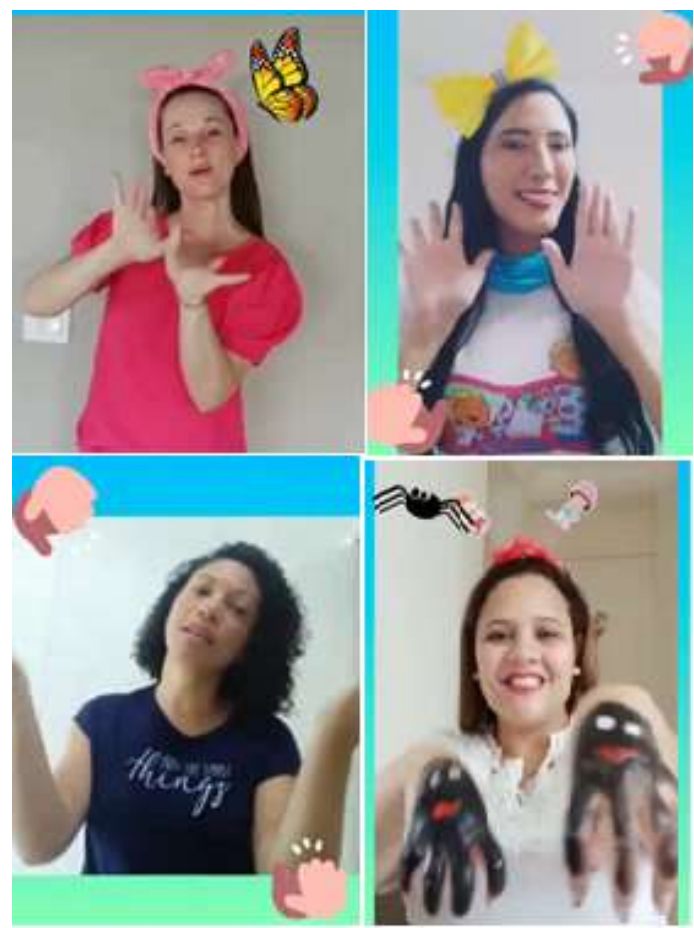

Figura 2 - Imagens do vídeo produzido pelas professoras para a semana das crianças Fonte: arquivo próprio (2020).

Criar uma maneira de se encontrar com as crianças para celebrar a alegria de uma data tão especial, amenizando os afetos tristes provocados pelo distanciamento social, tornou-se um desafio para os docentes e uma forma de resistir à imagem dogmática do pensamento de que só existe interação no ambiente escolar de modo presencial. Nesse contexto, o encontro com o inusitado da pandemia violentou o pensamento, pois, como afirma Deleuze (2003, p. 89), ao falar da relação entre signo e pensamento, "[...] sem algo que force a pensar, sem algo que violente o pensamento, este nada significa. Mais importante do que o pensamento é o que 'dá que pensar'".

Para Deleuze (2006, p. 135), o que é o “[...] próprio do novo, isto é, a diferença, é provocar no pensamento forças que não são as da recognição, [...] potências de um modelo totalmente distinto [...]". Para tanto, é preciso problematizar a imagem-representação, que é uma imagem fixa/pronta, buscando uma nova imagem, um novo pensamento, isto é, um pensamento sem imagem. Segundo o filósofo, o pensamento sem imagem é um pensamento não dado a priori, sem contornos predefinidos, que recusa a ideia do pensamento como representação e investe num pensamento como criação. Pensamento que experimenta possibilidades inesperadas. 
- Como vamos fazer para comemorar esse momento com as crianças e interagir com elas? E para aquelas que não têm acesso à internet? É preciso fazer um diagnóstico! Será que o vídeo vai ficar legal? Vou conseguir superar o nervosismo diante da câmera? (Redes de conversações com professoras Diário de Campo - 2020).

As indagações e incertezas fizeram parte do processo criativo que culminou na elaboração de vídeos pelas professoras e encontros com as crianças pelo aplicativo Google Meet, momento em que as professoras pensaram em sua prática docente de modo a levar outras possibilidades para o cotidiano escolar. Experimentar e nunca interpretar. Essa seria a única possibilidade de escapar às imagens dogmáticas do pensamento. À interpretação, Deleuze e Guattari (2011) opõem a experimentação. Foi isso o que fizeram as professoras em contexto de pandemia. Experimentaram as oportunidades. Criaram, resistiram, (re)existiram.

Assim, ao se abrirem ao pensamento sem imagem, produziram resistências, construíram novos agenciamentos, novos arranjos, conectaram desejos, pois, como afirmam Deleuze e Guattari (1976, p. 109), “[...] o desejo está sempre onde quer que haja algo a fluir ou a correr". Desejo entendido aqui como construção de agenciamentos e não como falta (DELEUZE, 2001), pois, assim entendido, leva-nos a desejar experimentar agenciamentos e nunca interpretar, levanos a procurar os bons encontros e agenciamentos que nos convêm. É nesse sentido que tudo se tornou matéria de experimentações, como nos disse a pedagoga: Estamos tentando, fazendo de tudo um pouco. Se vai dar certo não sei, mas estamos tentando (Redes de conversações com professores/as - Diário de Campo - 2020).

Assim, (re)existindo, foi preciso encontrar um modo de dar continuidade aos grupos de estudos que aconteciam semanalmente no ambiente escolar, já que o distanciamento social impediu o encontro presencial dos professores. Foi aí que, em meio a redes de conversações com as pedagogas, com a diretora, professoras e auxiliares de creche, optou-se por fazer encontros de forma on-line pelo aplicativo Google Meet, intercalando atividades síncronas e assíncronas.

Embora muitas dificuldades tenham sido vivenciadas nesse processo, como falha nas conexões, internet ruim, os encontros-formação possibilitaram outras novas imagens de pensamento. Imagens (des)enquadradas, em que movimentos curriculares foram sendo produzidos pelas telas dos computadores, atrelando possíveis para a docência em meio a novas aprendizagens e invenções. Sobre isso enunciaram as professoras:

- Foi uma experiência enriquecedora! Questionamos o viver do óbvio que muitas vezes nos acomete sem percebermos e que faz com que nos tornamos âncoras, ficamos agarradas. Também nos ajudou a pensar que não nascemos prontos e nunca ficaremos prontos, estamos em constante mudanças, nossas raízes perpassam por terrenos diversos e absorvem diferentes nutrientes.

- Eu achei ótimo! A gente quase não tem a oportunidade de conversar com os professores da universidade. Foi um modo de diminuir a distância entre a academia e a escola, saber o que pensam, o que está sendo estudado no momento. - A ideia de problematizar o trabalho coletivo foi bem legal! Eu tinha outras ideias sobre coletivo, sobre isso que você chama de "comum", matilha. Pra mim, só poderia dar certo se todos seguissem um padrão. Agora sei que não é bem assim. Posso entender por que existem tantos conflitos na escola (risos). (Redes de conversações com professoras - Diário de Campo - 2020).

Em relação à formação docente, Dias (2010, p. 5) nos sinaliza que é possível observar "[...] a não aceitabilidade hegemônica de uma formação, mas, ao contrário, ela se afirmar em termos de devir, no entre aprender e desaprender, cultivando as formas de problematizar, 
sempre provisórias." Assim, pensamos a formação não como um ato de transmissão de conhecimentos ou informação, pois “[...] uma informação é um conjunto de palavras de ordem. Quando nos informam, nos dizem o que julgam que devemos crer. Em outros termos, informar é fazer circular uma palavra de ordem." (DELEUZE, 1999, p. 10).

Então pensamos a formação como redes de conversações, em que o coletivo escolar expressa e compartilha suas experiências, trazendo novos sentidos para o coletivo e para o currículo. São espaçostempos ${ }^{4}$ criados que valorizam as singularidades, que evidenciam a multiplicidade de saberes, engendrado com os encadeamentos da experiência coletiva, criando possibilidades para outros modos de aprenderensinar.

Isso, porém, não quer dizer que a ideia do ensino remoto tenha sido adotada como "ideal" a ser seguido. Nas enunciações das professoras, foi possível cartografar intensidades desejantes, que anseiam pelos encontros presenciais com as crianças, pelos movimentos, pelos sorrisos/choros, pelos banhos de mangueira e de borrifadores, pelos barulhos, pelos cheiros, gostos, pelas conversas entre colegas de trabalho nos espaços da escola, pelos passeios e... e... e...

- Passeios? Êh, saudades! Ganhei o dia lembrando bons afetos, boas parcerias através dessas fotos. E os banhos de mangueira? Teve até banho de borrifadores.

- Nesse tempo de trabalho remoto esses aplicativos de vídeo ajudam a minimizar um pouco essa falta de olho no olho.

- Estar distante nos fez perceber o quanto temos a necessidade de estar perto.

- Nem me fale! Sinto um aperto no coração ao lembrar das crianças. Espero que isso tudo passe logo. (Redes de conversações com professoras - Diário de Campo - 2020).

Nesse sentido, para além de julgar entre certo e errado, se convém ou não convém e/ou o binarismo entre ensino remoto e o presencial, o que queremos destacar é a força de ação coletiva $\mathrm{na} / \mathrm{da}$ escola produtora de resistências às imagens reducionistas/representativas de espaçostempos de aprendizagem e formação de professores, aos modos de se fazerem currículos verticalmente orientados, impulsionando movimentos outros de formação e invenções curriculares em tempos de pandemia.

\section{Em busca do "tempo infantil" da escola em contexto de pandemia}

Acredito que essa "pausa" da pandemia seja para voltarmos diferentes. (Redes de conversações com professoras - Diário de Campo - 2020).

As provocações presentes nas enunciações de professoras levam à problematização do tempo da escola (KOHAN, 2020) e a nossa experiência do tempo. Acho que não deveria ter atividades para fazer na formação. Não tenho tempo para nada. Vivo numa correria louca! argumenta a professora em relação às atividades assíncronas propostas na formação de professores.

A professora alerta para o fato de estarmos cada vez mais mergulhados nessa "correria louca", e o tempo nos parece sempre mais acelerado, pois fomos afetados profundamente em relação a esse tempo khrónos, cronometrado. Para algumas pessoas, o trabalho remoto promoveu a junção do trabalho formal com as tarefas do lar, o que acarretou uma rotina mais acelerada. Assim, quanto maior for o número de tarefas nesse tempo cronológico, menos tempo

\footnotetext{
${ }^{4}$ Com escrita conjugada explicitada na expressão espaçostempos e em outros termos presentes no texto, pretendemos destacar a indissociabilidade dos sentidos, ampliando as conexões, tal qual propõe Alves (2009) com esse modo de escrever.
} 
e menos condições teremos para pensar/problematizar as questões da escola e menos tempo para vivenciar a intensidade das experiências.

Nesse sentido, pensar questões relacionadas ao tempo nos interessa bastante, pois “" [...] a maneira como nos relacionamos com o tempo afeta a maneira como nos relacionamos com todo o mundo, com o que fazemos com a vida e o que fazemos com nós mesmos" (KOHAN, 2018, p. 299). Nessa perspectiva, Kohan (2020, p. 7) nos indica três formas de temporalidade que vêm da Grécia antiga, a saber:

[...] khrónos é o tempo de relógio, do calendário, da instituição. É o tempo que não para, que segue movimentos uniformes, sucessivos, consecutivos, irreversíveis, qualitativamente indiferenciados. [...] Kairós é o tempo da oportunidade, o momento oportuno, a ocasião adequada para se experimentar algo como não se poderia experimentar em qualquer outro momento; é um tempo qualificado, preciso, singular, único. Aión é a duração no tempo; o tempo intensivo, da experiência, do acontecimento. Ele é puro presente. É o tempo daquelas experiências que nos fazem sentir que o presente dura, nas quais estamos como suspendidos no presente: a arte, o amor, a filosofia e, pensando na escola, a leitura, a escrita, o estudo.

Para o autor, essas temporalidades exercem importante influência na educação. O tempo khrónos, por exemplo, lembra-nos um tempo adulto, tempo de organizações pedagógicas, planejamentos, sequências didáticas, rotinas, horários cronometrados para essa ou aquela atividade. Kairós, entretanto, refere-se ao tempo das oportunidades que nascem do cruzamento do tempo cronológico com as nossas experiências, nossos afetos. E “[...] desse cruzamento resultam experiências pedagógicas oportunas e inoportunas" (KOHAN, 2020, p. 7).

Para falar do tempo Aion, Kohan (2020) tece sabiamente conexões com a infância, mostrando-nos que as crianças vivenciam esse outro modo de sentir o tempo. Tempo liberado de toda a interpretação (DELEUZE; GUATTARI, 2012) e que, desprendido das imagens dogmáticas do pensamento, faz-nos viver a intensidade das experiências como puro presente, pura experimentação. É esse tempo intensivo que Kohan (2020) chama de “tempo infantill, não porque corresponde ao período ou à faixa etária da criança, mas porque se revela como uma força do devir-criança ${ }^{5}$ que nos atravessa. Tempo de "[...] perguntar, do querer saber, do amar pensar, do criar, do brincar como modo de habitar o mundo..." (KOHAN, 2020, p. 7).

Observemos, pois, o enunciado da professora: Acredito que essa 'pausa' da pandemia seja para voltarmos diferentes. Ao se referir ao tempo pandêmico como uma "pausa", não quer dizer que o tempo khrónos tenha sido paralisado, pois ele continua a correr seguindo seu percurso de marcação, medindo o tempo, fixando as pessoas e as coisas. Entretanto, ao prosseguir seu argumento acreditando na possibilidade de produção de bons afetos, mesmo em contexto de pandemia, a professora manifesta esse outro modo de sentir o tempo, o desejo de viver outras experiências com/na escola.

Apesar de o tempo cronológico da escola ter sido profundamente afetado neste momento, com rotinas alteradas, sem horários de parquinho, lanches, entrada e saída, etc., Khrónos resiste e agora se apresenta de outros modos: horários para reuniões on-line, prazos para entrega de

\footnotetext{
${ }^{5}$ Ao propor o conceito de devir-criança, Deleuze e Guattari $(2012$, p. 97) não estavam tratando de uma metáfora nem mesmo de imitar as atitudes de uma criança como uma entidade molar, determinada por sua forma, mas “[...] 'uma' criança que coexiste conosco, numa zona de vizinhança ou num bloco de devir, numa linha de desterritorialização que nos arrasta a ambos [...]". Ao trabalhar tal conceito, Simonini (2019, p. 17) nos esclarece que se trata "[...] da composição com as possibilidades de invenção, imaginação, novidade e experimentação que atravessam a força da criança, no seguir linhas em aberto que não se restringem a um mundo pré-definido".
} 
atividades e preenchimento de anexos, tempo cronometrado para as formações on-line e outros afazeres. Porém, ao mesmo tempo em que se vivencia a "loucura" de Khrónos e as oportunidades de Kairós, também é possível vivenciar a intensidade de Aion em tempos de pandemia, como possibilidades para viver outros "possíveis" e, quem sabe, como possibilidade para voltarmos diferentes, como nos diz a professora. Portanto, Aion seria sim uma "pausa" em que a lei de Khrónos cessa de reinar, pois Aion é composto por linhas flutuantes (DELEUZE; PARNET, 1998) e não por contornos predefinidos.

Nessa perspectiva, o tempo da escola precisou ser (re)pensado em contexto de pandemia, já que as atividades presenciais foram suspensas. Kohan $(2020$, p. 6) afirma que "[...] a pandemia provoca uma desaceleração e até uma suspensão da experiência do tempo educativo pela possibilidade de repensar os sentidos e as condições do que se faz". E o que nos chama a atenção nesse movimento de cartografia dos afetos produzidos pela força de ação coletiva na/da escola em tempos de pandemia são os diferentes modos de habitar e existir o cotidiano escolar, considerando as múltiplas formas de vivenciar o tempo da escola para além das imagens dogmáticas de pensamento.

Nos encontros-formação em tempos de pandemia, imagens-fotografias da escola foram capturadas pelas professoras e apresentadas, levando-nos a pensar nos ventos que circulam livremente pelo vazio do pátio, nos materiais que pacientemente aguardam para serem utilizados, nas cores mais cinzentas devido à poeira que lhes cobre, nas marcas que não existiam naquele lugar, como avisos, recados, regras para garantir o distanciamento social... e tantas outras imagens que, em composição com as redes de conversações, possibilitam a criação de outros possíveis em meio aos espaçostempos das formações on-line. Composições em que afetos e afecções são produzidos, possibilitando pensar os modos como professores inventam e resistem como corpo coletivo nesse tempo de pandemia, bem como em outros modos de sentir/viver o tempo da escola.

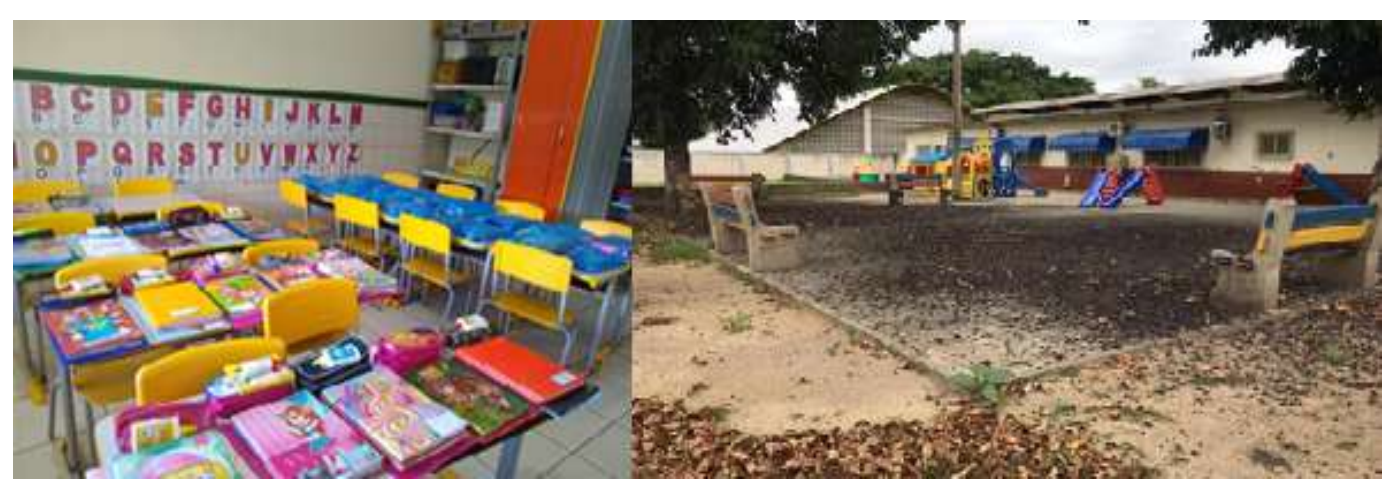

Figura 3 - Imagens-fotografias de sala de aula e pátios vazios em tempos de pandemia Fonte: arquivo próprio (2020).

E nos entremeios dos processos formativos pelas telas dos computadores, as redes de conversações com professoras, em composição com as imagens-fotografias, imagens-literatura, vídeos, dentre outros, expressaram o viver das intensidades das experiências como puro presente. Forças de um tempo Aion que, segundo Deleuze e Guattari (2012, p. 51),

[...] é o tempo indefinido do acontecimento, a linha flutuante que só conhece velocidades, e ao mesmo tempo não para de dividir o que acontece num já-aí e um ainda não-aí, um tarde-de-mais e um cedo-demais simultâneos, um algo que ao mesmo tempo vai se passar e acaba de se passar. 
Talvez seja realmente isso que precisamos fazer, isto é, experimentar/viver os tempos da escola de outro modo, abrirmo-nos às intensidades, assim como fizeram as professoras nos encontros-formação. Ir em busca do "tempo infantil" da escola. Tempo em que nos permitimos perguntar, querer saber, amar pensar, habitar o inusitado da pandemia com nossos modos brincantes de existir, experimentando, em vez de interpretar; assim como fazem, de forma muito peculiar, as crianças. Modos que fortalecem a composição de um corpo coletivo mais potente, como força de ação coletiva se fazendo presente no presente.

Buscar o "tempo infantil" da escola em contexto de pandemia é, como nos inspira Kohan (2020, p. 7), viver "[...] o tempo da educação como uma experiência durativa, intensiva, que prolonga a temporalidade presente: o acontecimento que interrompe a sequência cronológica e permite uma experiência que se faz presencial, em tempo presente". É devir-criança, seguindo linhas em aberto que não se restringem a um mundo predefinido (SIMONINI, 2019). É (des)enquadrar imagens na busca de um pensamento sem imagem. É criar, (re)inventar, resistir, (re)existir em tempos extremamente difíceis.

Por isso, apostamos na relação com o outro e na cartografia das experiências dos docentes por entendê-las como potência coletiva que se expande em meio às redes de conversações e fissuram as prescrições e normatizações impostas, dando passagem às micropolíticas e movimentos de resistências nas formações de professores.

\section{Algumas considerações}

É inegável pensar que conexões foram criadas por redes intencionais e tecnológicas com o uso de dispositivos eletrônicos e atravessaram o cotidiano de professoras no contexto atual da educação. A docênciadesejo, que cria, inventa e resiste, teve como desafio um cotidiano escolar de distâncias e incertezas. O ensino remoto provocou modificações nas rotinas de famílias e nas relações entre as pessoas.

Pudemos perceber, através das redes de conversações, que processos de resistências surgiram desses encontros, tecendo redes de solidariedade entre professores e problematizações. Em meio às composições dos docentes, a força dos afetos e das afecções afirmou a vida e a diferença por movimentos imprevisíveis e que, por questionamentos do passado e por tentativas de romper com as ações normatizantes, passam a disparar alternativas para o presentefuturo. As capturas realizadas na pesquisa foram para além de afetos tristes, dotados de medos, inseguranças, de trabalhos limitantes, a deterioração das estruturas escolares pelo tempo, as salas de aulas vazias, chegando às aprendizagens e às possibilidades de pensar e vivenciar a escola a partir da força de ação coletiva que possuem experiências singulares compartilhadas por professores. As experimentações e suas trocas favorecem o surgimento de possíveis.

Pelas formações detectamos pontos de vistas diferentes, modos de fazer, propostas de atividades, o que torna a relação dinâmica e plural, afinal, a força de ação coletiva da escola impulsiona movimentos curriculares inventivos que burlam, fogem, transformam-se e não foram extintos nesses tempos de pandemia. A pandemia exigiu um enfrentamento no novo espaçotempo "tela". A escola se fez proliferando redes que fazem surgir, afirmar, enfrentar, resistir, criando novas composições e combinações curriculares.

Assim, em meio às (re)existências, o desejo de retomada dos ambientes escolares também é latente. Sentir o outro tem feito falta. Os fragmentos de enunciações apresentados no texto revelam o desejo de conhecer, descobrir, estar perto do outro, seja por indagações da vida particular, seja por tentar encontrar possibilidades para que o cotidiano escolar viva experiências que celebrem a alegria e que, muitas vezes, denotam uma nostalgia, reforçando os laços e fazendo pensar o comum. 
Desse modo, podemos afirmar que os deslizamentos provocados pelas professoras inventam modos de agir a partir da experiência e, por isso, dão pistas que intencionam vivenciar um "tempo infantil". Nesse sentido, as professoras (re)existem, criando experiências coletivas, fissurando os modos de existências impostos, fazendo dialogar potências do agir para ampliar as possibilidades de aprendizagens e de existência.

\section{Referências}

ALVES, N. Cotidiano, imagens e narrativas: Programa um Salto para o Futuro. MEC. 2009. Disponível em: http://portaldoprofessor.mec.gov.br. Acesso em: 15 jan. 2019.

CARVALHO, J. M. O cotidiano escolar como comunidade de afetos. Petrópolis: DP et Alii, 2009.

CARVAlHO, J. M.; SILVA, S. K. da; DELBONI, T. M. Z. G. F. Currículos como corpos coletivos. Currículo sem Fronteiras, Porto Alegre, v. 18, n. 3, p. 801-818, set./dez./ 2018.

DELEUZE, G. O ato de criação. Jornal Folha de São Paulo, Caderno Mais, p. 4-5, 27 jun. 1999.

DELEUZE, G. $O$ abecedário de Gilles Deleuze. Entrevista concedida em vídeo a Claire Parnet. Vídeo. Editado no Brasil pelo Ministério de Educação, "TV Escola”, série Ensino Fundamental, 2001.

DELEUZE, G. Proust e os signos. 2. ed. Tradução de Antonio Piquet e Roberto Machado. Rio de Janeiro: Forense Universitária, 2003.

DELEUZE, G. Diferença e repetição. Tradução de Luiz Orlandi e Roberto Machado. Rio de Janeiro: Graal, 2006.

DELEUZE, G.; GUATTARI, F. O que é filosofia? Tradução de Bento Prado Jr. e Alberto Alonso Muñoz. 3. ed. São Paulo: Editora 34, 2010.

DELEUZE, G.; GUATTARI, F. O Anti-Édipo: capitalismo e esquizofrenia. Tradução Joana Morais Varela e Manuel Maria Carrilho. Rio de Janeiro: Imago, 1976.

DELEUZE, G.; GUATTARI, F. Mil Platôs: capitalismo e esquizofrenia. v. 1. Tradução de Ana Lúcia Oliveira, Aurélio Guerra Neto e Celia Pinto Costa. 2. ed. São Paulo: Ed. 34, 2011.

DELEUZE, G.; GUATTARI, F. Mil Platôs: capitalismo e esquizofrenia. v. 4. São Paulo: Ed. 34, 2012.

DELEUZE, G.; PARNET, C. Diálogos. Tradução: Eloisa Araujo Ribeiro. São Paulo: Editora Escuta, 1998.

DIAS, R. Arte que nos move: oficinas de formação inventiva de professores. In: REUNIÃO ANPED, 33., 2010, Caxambu, MG. Anais... Caxambu, MG. Disponível em: http://33reuniao.anped.org.br/33encontro/app/webroot/files/file/Trabalhos\%20em\%20PDF/G T24-6493--Int.pdf. Acesso em: 26 set. 2020. 
KOHAN, W. A escola como experiência: entrevista com Walter Omar Kohan. Revista Eletrônica de Educação, v. 12, n. 4, jan./abr. 2018. Disponível em: http://www.reveduc.ufscar.br/index.php/reveduc/article/view/. Acesso em: 18 ago. 2019.

KOHAN, W. Tempos da escola em tempo de pandemia e necropolítica. Práxis Educativa, Ponta Grossa, v. 15, p. $\quad 1-9, \quad 2020 . \quad$ Disponível em: https://revistas2.uepg.br/index.php/praxiseducativa/article/view/16212. Acesso em: 17 nov. 2020.

SIMONINI, E. A alegria subversiva de devir-criança. Momento - diálogos em educação, v. 28, p. 11-25, 2019.

SPINOZA, B. de. Ética. Tradução de Tomaz Tadeu da Silva. Belo Horizonte: Autêntica, 2009.

\section{Sobre as autoras}

Hociene Nobre Pereira Werneck. Mestranda do Programa de Pós-graduação de Mestrado Profissional em Educação - PPGMPE/Ufes.

E-mail: hociene@gmail.com.

Lívia Camporez Giuberti. Mestre em Educação pelo Programa de Pós-graduação de Mestrado Profissional em Educação - PPGMPE/Ufes.

E-mail: lcgiuberti@hotmail.com. 